\section{Differential Superiority of Heavy Charged-Particle Irradiation to X-Rays: Studies on Biological Effectiveness and Side Effect Mechanisms in Multicellular Tumor and Normal Tissue Models}

\author{
Stefan Walenta and Wolfgang Mueller-Klieser* \\ Institute of Pathophysiology, University Medical Center, University of Mainz, Mainz, Germany
}

This review is focused on the radiobiology of carbon ions compared to X-rays using multicellular models of tumors and normal mucosa. The first part summarizes basic radiobiological effects, as observed in cancer cells. The second, more clinically oriented part of the review, deals with radiation-induced cell migration and mucositis. Multicellular spheroids from V79 hamster cells were irradiated with X-rays or carbon ions under ambient or restricted oxygen supply conditions. Reliable oxygen enhancement ratios could be derived to be $2.9,2.8$, and 1.4 for irradiation with photons, ${ }^{12} \mathrm{C}^{+6}$ in the plateau region, and ${ }^{12} \mathrm{C}^{+6}$ in the Bragg peak, respectively. Similarly, a relative biological effectiveness of 4.3 and 2.1 for ambient $\mathrm{pO}_{2}$ and hypoxia was obtained, respectively. The high effectiveness of carbon ions was reflected by an enhanced accumulation of cells in $G_{2} / M$ and a dose-dependent massive induction of apoptosis. These data clearly show that heavy charged particles are more efficient in sterilizing tumor cells than conventional irradiation even under hypoxic conditions. Clinically relevant doses (3 Gy) of X-rays induced an increase in migratory activity of U87 but not of LN229 or HCT116 tumor cells. Such an increase in cell motility following irradiation in situ could be the source of recurrence. In contrast, carbon ion treatment was associated with a dose-dependent decrease in migration with all cell lines and under all conditions investigated. The radiation-induced loss of cell motility was correlated, in most cases, with corresponding changes in $\beta_{1}$ integrin expression. The photon-induced increase in cell migration was paralleled by an elevated phosphorylation status of the epidermal growth factor receptor and AKT-ERK1/2 pathway. Such a hyperphosphorylation did not occur during ${ }^{12} \mathrm{C}^{+6}$ irradiation under all conditions registered. Comparing the gene toxicity of $\mathrm{X}$-rays with that of particles using the $\gamma \mathrm{H} 2 \mathrm{AX}$ technique in organotypic cultures of the oral mucosa, the superior effectiveness of heavy ions was confirmed by a twofold higher number of foci per nucleus. However, proinflammatory signs were similar for both treatment modalities, e.g., the activation of $\mathrm{NFKB}$ and the release of IL6 and IL8. The presence of peripheral blood mononuclear cell increased the radiation-induced release of the proinflammatory cytokines by factors of 
2-3. Carbon ions are part of the cosmic radiation. Long-term exposure to such particles during extended space flights, as planned by international space agencies, may thus impose a medical and safety risk on the astronauts by a potential induction of mucositis. In summary, particle irradiation is superior to gamma-rays due to a higher radiobiological effectiveness, a reduced hypoxia-induced radioresistance, a multicellular radiosensitization, and the absence of a radiation-induced cell motility. However, the potential of inducing mucositis is similar for both radiation types.

Keywords: radiobiology, particle irradiation, oxygen enhancement ratio, relative biological effectiveness, organotypic tumor and mucosa cultures, mucositis, cell migration

\section{INTRODUCTION}

This article summarizes data which we have acquired in close collaboration with a number of scientists at the Gesellschaft fuer Schwerionenforschung (GSI) Darmstadt, Germany, for more than one decade. At the beginning of this collaboration, little was known about the basic radiobiology of particle irradiation, although there was emerging evidence already at that time for the usefulness of a carbon ion radiotherapy in clinical oncology (1). Consequently, the ultimate goal of the interactive work at the GSI accelerator was to augment our knowledge on biological effects of heavy charged particles in malignant tumors and in healthy tissue in comparison to the effect of conventional X-rays under equivalent conditions.

In most of the experiments, a carbon- $12\left({ }^{12} \mathrm{C}^{6+}\right)$ beam was applied in the scanning mode either in the extended Bragg peak or in the plateau region at $227 \mathrm{MeV} /$ nucleon. Conventional $\mathrm{X}$-rays served as a reference, and $\mathrm{X}$-ray equivalent doses were derived for heavy charged particle irradiation. Since beam-time is highly cost-intensive and since there is a pronounced competition among scientists for the acquisition of beam-time, design and performance of experiments with heavy charged particles are subjected to practical limitations by the restricted availability of the particle beam. This reduces the number of experiments within a given time frame and consequently restricts statistical corroboration of findings by multiple approaches. This has to be kept in mind, when data from particle irradiation are compared with those from other assays.

All irradiation experiments were carried out on cultured cells using various tumor and normal cell models. Besides conventional single cell cultures, complex three-dimensional (3D) cell cultures were used; these included organotypic cultures of the human oral mucosa with or without immune cells, planar cell multilayers of WiDr colon adenocarcinoma cells or of $\mathrm{SiHa}$ cervix carcinoma cells, and multicellular spheroids (MCS) from V79 cells. With a few exceptions, irradiation was routinely performed under standardized cell culture conditions at $37^{\circ} \mathrm{C}$ and ambient $(20 \%$ $\mathrm{O}_{2}$ ) or reduced $\left(\mathrm{pO}_{2}\right.$ close to $0 \mathrm{mmHg}$ ) oxygen supply conditions.

"Classical" radiobiological endpoints, such as clonogenic cell survival, spheroid volume growth, or cell cycle effects as a function of radiation dose, were used to quantify the efficiency of particle versus conventional radiation. Furthermore, the relative biological effectiveness (RBE) and the oxygen enhancement ratio (OER) for the two radiation modalities were derived. One specific endpoint was cell migration and motility in $2 \mathrm{D}$ and $3 \mathrm{D}$ conditions under the impact of irradiation. The gene toxicity of both radiation types in normal tissue was quantified using the $\gamma \mathrm{H} 2 \mathrm{AX}$ technique in organotypic mucosa cultures. In this multicellular model, assays for early events of a radiation-induced mucositis, such as activation of the transcription factor NFKB or release of cytokines IL6 and IL8, were applied. The cocultivation of the mucosa model with human peripheral blood mononuclear cells (PBMCs) revealed a significant role of immune cells in the emergence of radiation-related mucositis.

Following the introduction, the experimental part of this review article is subdivided into three major chapters. The first chapter deals with our data related to the basic radiobiology of carbon ion irradiation compared to that of conventional gammaradiation. This includes the relative biological effectiveness, the oxygen effect, and the multicellular radioresistance. The second chapter is focused on our findings regarding clinical aspects of undesirable side effects of the two radiation types considered. These aspects refer to radiation-induced cell motility and to radiation-associated mucositis. The third chapter of this review links our own data to findings from the literature. For many years, radiobiological studies on heavy charged particles have remained sparse, but very recently, there is a tremendous increase in the number of reports on radiobiology of heavy ions, on their clinical use, as well as on a combination of their radiobiological and clinical aspects. Consequently, the intention of the third chapter of this review is by no means to give a comprehensive review of the literature on particle irradiation, but rather to present a selection of very recent reports that are closely related to the data presented here. The final paragraph of this review presents a brief resume of the article.

\section{BASIC RADIOBIOLOGY OF HEAVY CHARGED PARTICLES}

\section{RBE and OER Values for Carbon Ion Irradiation of Multicellular V79 Spheroids}

Ever since the pioneering work of Robert Sutherland and colleagues (2), reviewed in Ref. (3), MCS represent classical 3D cell models in radiation research. Based on a sabbatical in Sutherland's laboratory (4) and on the pioneer's personal assistance as a Humboldt awardee at the University of Mainz (5), one of us set up a state-of-the-art spheroid laboratory at our research institute. 
Within the frame of a number of different research projects, we collected a large amount of data on $3 \mathrm{D}$ versus $2 \mathrm{D}$ growth characteristics, on 3D interaction between tumor and immune cells, or on tumor microenvironment with regard to hypoxia, hypoglycemia, acidosis, and other factors (6).

Occasionally, these data sparked the interest of scientists at the GSI in using our expertise with the spheroid technology for the exploration of heavy charged particle radiobiology. Spheroids from immortalized and tumorigenic V79 hamster cells have been frequently used in radiobiological investigations, and we decided to initiate our studies on heavy ion radiobiology with this spheroid type having an abundance of comparative data from X-ray experiments.

Multicellular spheroids from V79 cells with $200 \mu \mathrm{m}$ in diameter were irradiated with X-rays or carbon ${ }^{12} \mathrm{C}^{6+}$ ions under elevated, ambient, or restricted oxygen supply conditions. From previous microelectrode measurements, the oxygen tension distribution within the MCS as a function of the external oxygen tension was known, which made it possible to exactly relate the local oxygen to the radiation effects. For reasons of simplicity, average numbers for the environmental oxygen tension $\left(\mathrm{pO}_{2}\right)$ in $\mathrm{mm} \mathrm{Hg}$ are given for characterizing the experimental conditions. Figure 1 shows clonogenic cell survival curves for V79 MCS irradiated with $\mathrm{X}$-rays (Figure 1A) in environmental $\mathrm{pO}_{2}$ values of $144 \mathrm{mmHg}$ (circles), $35 \mathrm{mmHg}$ (squares), and $0 \mathrm{mmHg}$ (diamonds) or irradiated with ${ }^{12} \mathrm{C}^{6+}$ ions in the extended Bragg peak (Figure 1B) in environmental $\mathrm{pO}_{2}$ values of $690 \mathrm{mmHg}$ (circles) and $0 \mathrm{mmHg}$ (diamonds). It is obvious that (i) survival curves after particle irradiation are close to being linear with almost no shoulder compared to the X-ray data and (ii) the oxygen effect is much less pronounced with particle compared to photon irradiation. Survival curves of V79 single cells were almost identical with that
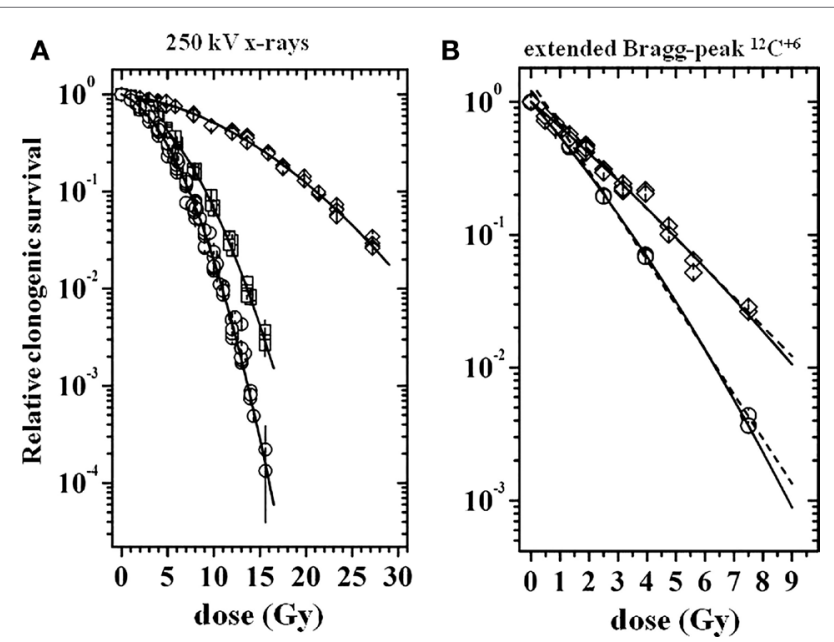

FIGURE 1 | Relative clonogenic survival of cells from V79 MCS as a function of dose [modified according to Ref. (7)]. (A) Following X-ray irradiation at external $\mathrm{pO}_{2}$ values of $144 \mathrm{mmHg}$ (circles), $35 \mathrm{mmHg}$ (squares), and $0 \mathrm{mmHg}$ (diamonds), (B) following ${ }^{12} \mathrm{C}^{6+}$ irradiation in the extended Bragg peak at external $\mathrm{pO}_{2}$ values of $690 \mathrm{mmHg}$ (circles) and $0 \mathrm{mmHg}$ (diamonds); dose values represent $\mathrm{X}$-ray equivalent dose. of V79 spheroids with no indication of a multicellular resistance or contact effect (data not shown). Irradiation of V79 MCS with carbon ions in the plateau region $\left(227 \mathrm{MeV} /\right.$ nucleon $\left.{ }^{12} \mathrm{C}^{6+}\right)$ in the same oxygen atmospheres as used with $\mathrm{X}$-ray treatment produced survival curves that were almost identical with those from photon irradiation (data not shown).

The survival curves of V79 MCS displayed in Figure 1 were fitted with the linear quadratic model. This was used for deriving reliable OER and relative biological effectiveness (RBE values). OER values at several survival levels $S(=37,10,1$, and $0.1 \%)$ were calculated as the ratio of doses to achieve a given survival under hypoxia compared to normoxia. Averages were derived from the individual values, which varied with $S$ by around $5 \%$. A corresponding procedure was used for the derivation of RBE, which was defined as the ratio of X-ray dose to that of particle radiation to reach a given $S$. These data are compiled in Table $\mathbf{1}$. Besides the very low OER value of 1.40 for particle irradiation, the RBE value of heavy charged particles is remarkably high at 4.31. Further details on the data evaluation were published earlier (7).

Furthermore, the high effectiveness of heavy charged particles in the extended Bragg peak compared to conventional radiation was reflected by a massive, dose-dependent induction of apoptosis [quantified by the TUNEL assay (7)], as shown in Figure 2. Although a respective curve for the extended Bragg peak induction of apoptosis under ambient oxygen conditions could not be assessed in this set of experiments for technical reasons, explorative data were indicative of an absence of an oxygen effect with regard to apoptotic cell kill [for further details, see Ref. (7)]. All data obtained in this spheroid study clearly show that heavy charged particles are more efficient in sterilizing tumor cells than conventional irradiation even under hypoxic conditions.

\section{Unexpected Multicellular Radiosensitization in Human Colon Adenocarcinoma-Derived Multilayer Cells}

Planar cell multilayers in comparison with monolayer cultures of WiDr and SiHa human colon adenocarcinoma-derived cells were used for investigations on the role of cell cycle effects in the treatment with photon or particle irradiation. Development of a special cryostat sectioning technique made it possible to assess histology and growth characteristics of the planar 3D model (8). This is exemplified by Figure 3, with Figure 3A displaying cryostat sections that were cut perpendicular to the multilayer

TABLE 1 | Oxygen enhancement ratio (OER) and relative biological effectiveness (RBE) values derived from the clonogenic survival curves shown in Figure 1 after irradiation in atmospheres with a $\mathrm{pO}_{2}$ of $690 \mathrm{mmHg}$ or $145 \mathrm{mmHg}$ (aerobic) or $0 \mathrm{mmHg}$ (hypoxic).

\begin{tabular}{lccc}
\hline Radiation type & OER & \multicolumn{2}{c}{ RBE } \\
\cline { 3 - 4 } & & Aerobic & Hypoxic \\
\hline X-rays & 2.87 & 1.00 & 1.00 \\
Ext. Bragg peak & 1.40 & 2.11 & 4.31
\end{tabular}



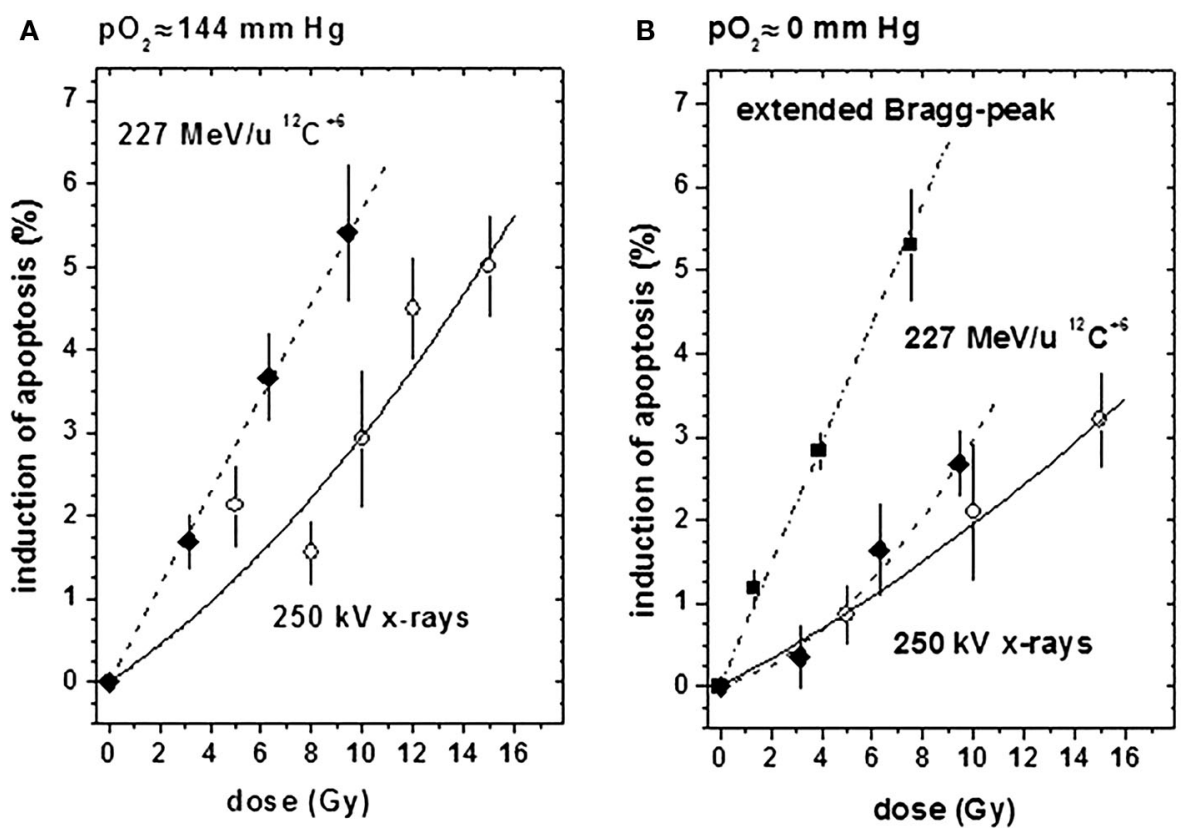

FIGURE 2 | Induction of apoptosis (relative to untreated controls) by X-ray (open circles) or ${ }^{12} \mathrm{C}^{6+}$ irradiation in the plateau region (filled diamonds) or in the extended Bragg peak (filled squares) under ambient or hypoxic oxygen supply conditions [modified according to Ref. (7)]. (A) At an external $\mathrm{pO}_{2}$ of $144 \mathrm{~mm} \mathrm{Hg}$ and $(\mathbf{B})$ at an external $\mathrm{pO}_{2}$ of $0 \mathrm{~mm} \mathrm{Hg}$.

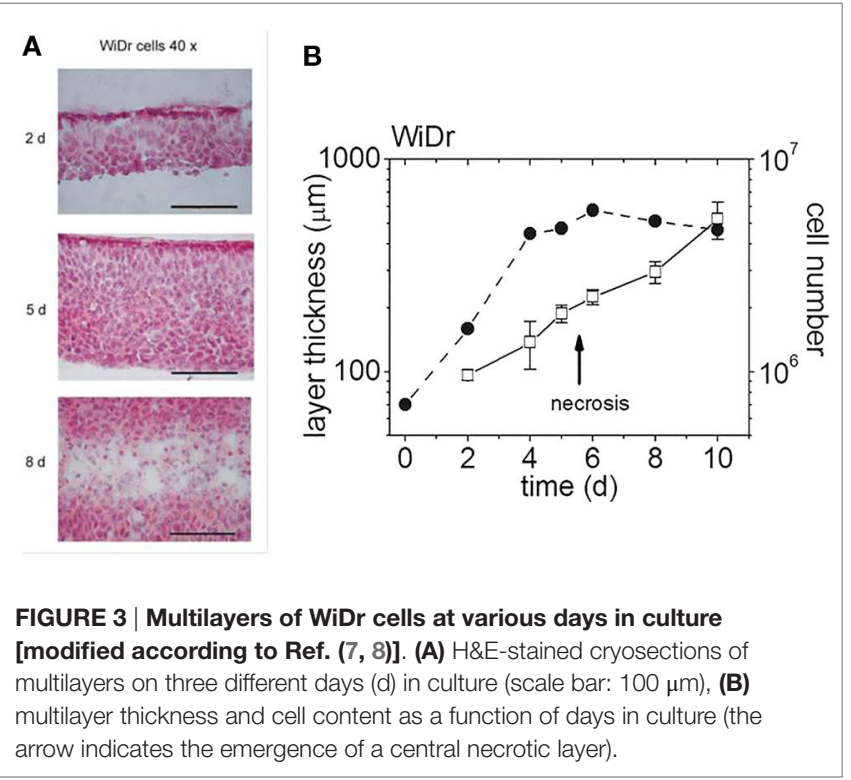

plane at three different times of growth for both cell lines considered. Figure 3B shows the multilayer thickness and viable cell content as a function of time in culture. Obviously, the total layer thickness is expanding continuously after the emergence and expansion of a central necrotic layer, whereas the total number of viable cells is stagnating. As such, planar cellular multilayers grow in a way, which is very similar to that of MCS despite the different diffusion geometries.

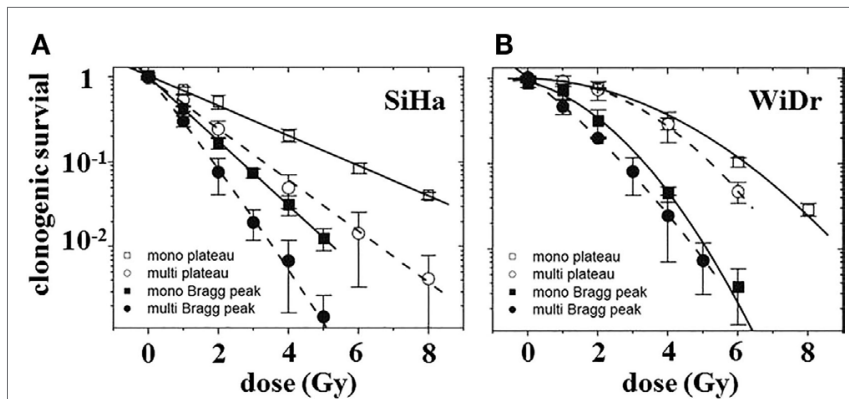

FIGURE 4 | Clonogenic survival of cells in monolayer (squares) or multilayer (circles) culture as a function of dose after carbon-ion irradiation in the plateau region ( $370 \mathrm{MeV} / \mathrm{nucleon}$; open symbols) or in the extended Bragg peak [closed symbols; modified according to Ref. (8)]. (A) SiHa cells $(n=4)$ and (B) WiDr cells $(n=2-3)$.

Unexpectedly, there was a multicellular radiosensitization of multi- versus monolayers under all treatments considered, as demonstrated by standardized clonogenic survival curves for ${ }^{12} \mathrm{C}^{6+}$ ion irradiation in the plateau region and the Bragg peak (Figure 4). This is in contrast to the generally detected multicellular radioresistance. The phenomenon was attributable, at least in parts, to a difference in the proportion of cells in the $G_{0} / G_{1}$ phase between the two culture types used. Furthermore, Figure 4 illustrates cell line-dependent differences in the type of cell survival curves: whereas WiDr cells exhibit "classical" shoulder curves except for Bragg peak particle irradiation, SiHa cell survival curves are very close to linearity with all treatments considered. 
This difference may indicate a different extent of DNA repair in these two cell lines due to either a different intensity/quality of DNA damage or different repair capacities.

Flow cytometric studies showed that X-rays induced a $G_{2} / M$ arrest, which was considerably prolonged in multi- compared to monolayers (Figure 5A). After Bragg peak irradiation of monolayers, the arrest time was increased compared to X-rays by $12-24 \mathrm{~h}$, and more cells were arrested than with X-rays (Figures 5A,B). However, in multilayers, both radiation modalities lead to similar growth arrests (see Figures 5A,B).

In essence, our data obtained in the multilayer project contribute to accumulating results in the literature regarding differences in biological properties and molecular mechanisms between 2D and 3D culture systems. Under many aspects, 3D planar cellular multilayers and 3D spherical cellular aggregates share common properties and behave in similar ways. On the other hand, multilayers tend to show a small but reproducible multicellular radiosensitization, whereas most spheroids exhibit a multicellular resistance. It is worth noting that this effect is even more pronounced with heavy charged particles than with photons [for further details on planar multilayers, see Ref. (8)].

\section{CLINICAL ASPECTS OF POTENTIAL SIDE EFFECTS OF HEAVY CHARGED PARTICLE IRRADIATION}

\section{Differential Effects of Radiation on Cell Migration Depending on Radiation Type and Cell Line}

When we initiated this project, there was an ongoing controversy within the science community about radiation-related modulation of tumor cell migration, mainly with regard to irradiation of glioblastomas (GBMs). The cellular motility of certain tumor cell lines is enhanced under in vitro conditions by sublethal doses of photon irradiation, as we and others have previously reported (9-11). In contrast, several other studies demonstrated that either similar sublethal or slightly higher doses impair GBM cell migration and invasion (12) or fail to modify these cell functions (13). The clarification of the respective controversy is clinically highly relevant: if therapeutic irradiation would enhance cell motility, tumor cells may leave the therapeutic field without receiving a cytotoxic dose and may thus be a source of recurrence. Some
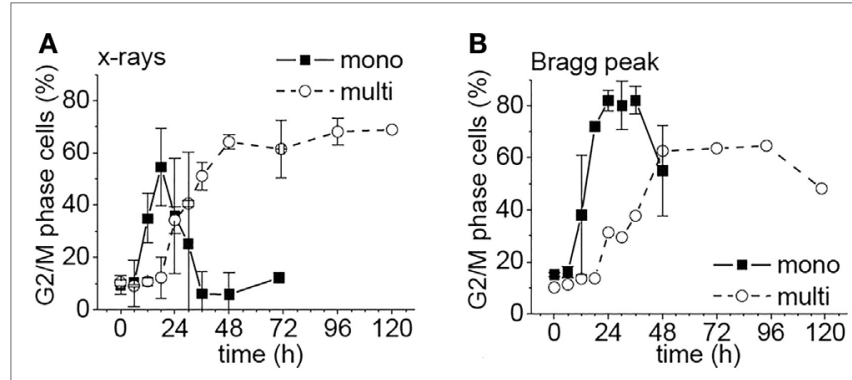

FIGURE 5 | Percentage of WiDr cells from mono- or multilayers in $\mathrm{G}_{2} / \mathrm{M}$ phase as a function of time after irradiation [modified according to Ref. (8)] with (A) X-rays and (B) carbon ions. recent data were suggestive of heavy charged particle irradiation to consistently reduce the migratory potential of tumor cells, but the respective study was lacking parallel evaluation of radiationinduced cell killing (14).

Recent therapeutic strategies target the epidermal growth factor receptor (EGFR), which is overexpressed in about $40-50 \%$ of GBMs (15). There is evidence in the literature for such anti-EGFR therapeutics to improve the efficacy of conventional radiotherapy (16). EGFR is a member of the cell-surface receptor family ErbB and functions as an oncogene. Activation of EGFR by binding of its specific ligands, including epidermal growth factor (EGF), leads to dimerization of the receptor and subsequently to autophosphorylation of its tyrosine-kinase domain. Following activation, the EGFR kinase stimulates a number of cellular signaling cascades, such as the phosphatidylinositol-3-kinase (PI3K)/AKT or the mitogen-activated protein kinase (MAPK) pathway (17). Thereby, numerous cellular responses are precisely regulated, such as proliferation, cell survival, and cell migration. EGF-induced EGFR activation has been shown to promote tumor cell migration (18). In addition to auto- and paracrine stimulation, it remains to be clarified whether therapies, such as radiotherapy, induce EGFR activation and pro-proliferative signaling directly or indirectly via production of radicals. Before starting our research in this field, no data existed with respect to EGFR activation by heavy charged particle irradiation.

Considering this background information, we initiated investigations on the impact of carbon ion irradiation on GBM cell motility and EGFR-related cell signaling in vitro. Most cell migration data were generated in "classical" Boyden (or transwell) chamber assays. Core proteins and phospho-proteins were analyzed with Western Blotting.

Investigations on U87 and LN229 glioma cells (with overexpression of $\mathrm{EGFR}^{++}$) showed that the migratory response of cancer cells to radiation is dependent on radiation dose, as well as on cell and radiation type. Clinically relevant doses (2 or $3 \mathrm{~Gy}$ ) of X-rays induced a small, but consistent and significant, increase in migratory activity of U87, but not of LN229, as illustrated in Figure 6A. ${ }^{12} \mathrm{C}^{6+}$ ion treatment was associated with a dose-dependent decrease in migration with all cell lines and under all conditions investigated (Figure 6B). The radiationinduced loss of cell motility was correlated, in most cases, with corresponding changes in $\beta_{1}$ integrin expression $(9,14)$. The photon-induced increase in cell migration in U87 glioma cells was paralleled by an elevated phosphorylation status of the EGFR and AKT-ERK1/2 pathway (see Figures 7 and 8). Such a hyperphosphorylation did not occur during ${ }^{12} \mathrm{C}^{6+}$ irradiation under all conditions registered (see Figures 7 and 8). Using a $3 \mathrm{D}$ collagen type I invasion and migration model, glioma cell migration remained unaffected by irradiation with either photon or particles, despite the induction of massive gene toxicity as determined by the $\gamma \mathrm{H} 2 \mathrm{AX}$ technique (13).

On the one hand, with a few exceptions, our in vitro findings on the interrelationship between irradiation and tumor cell migration are in accordance with data from the literature (14, $20,21)$. On the other hand, in vivo studies are warranted for the evaluation of the clinical significance of this issue. 

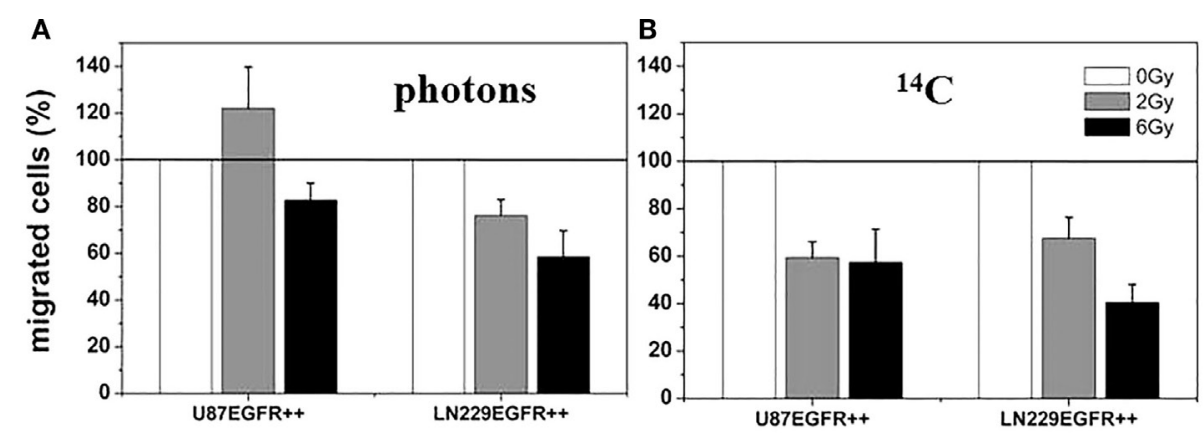

FIGURE 6 | Relative cell migration $24 \mathrm{~h}$ after photon and ${ }^{12} \mathrm{C}$ heavy ion irradiation. U87 EGFR ${ }^{++}$and LN229 EGFR ${ }^{++}$were irradiated with single doses of 2 and 6 Gy of photon radiation, respectively (A) and ${ }^{12} \mathrm{C}$ heavy ions (B) and migrated cells were counted after Boyden Chamber assay. The relative mean numbers of migrated cells \pm SD of at least three independent experiments are plotted with the migration of untreated cells set to $100 \%$. All differences between treated and untreated cells are significant $(p<0.05, t$-test). There was no significant change in cell viability under all conditions investigated (data not shown) [modified according to Ref. (19)].
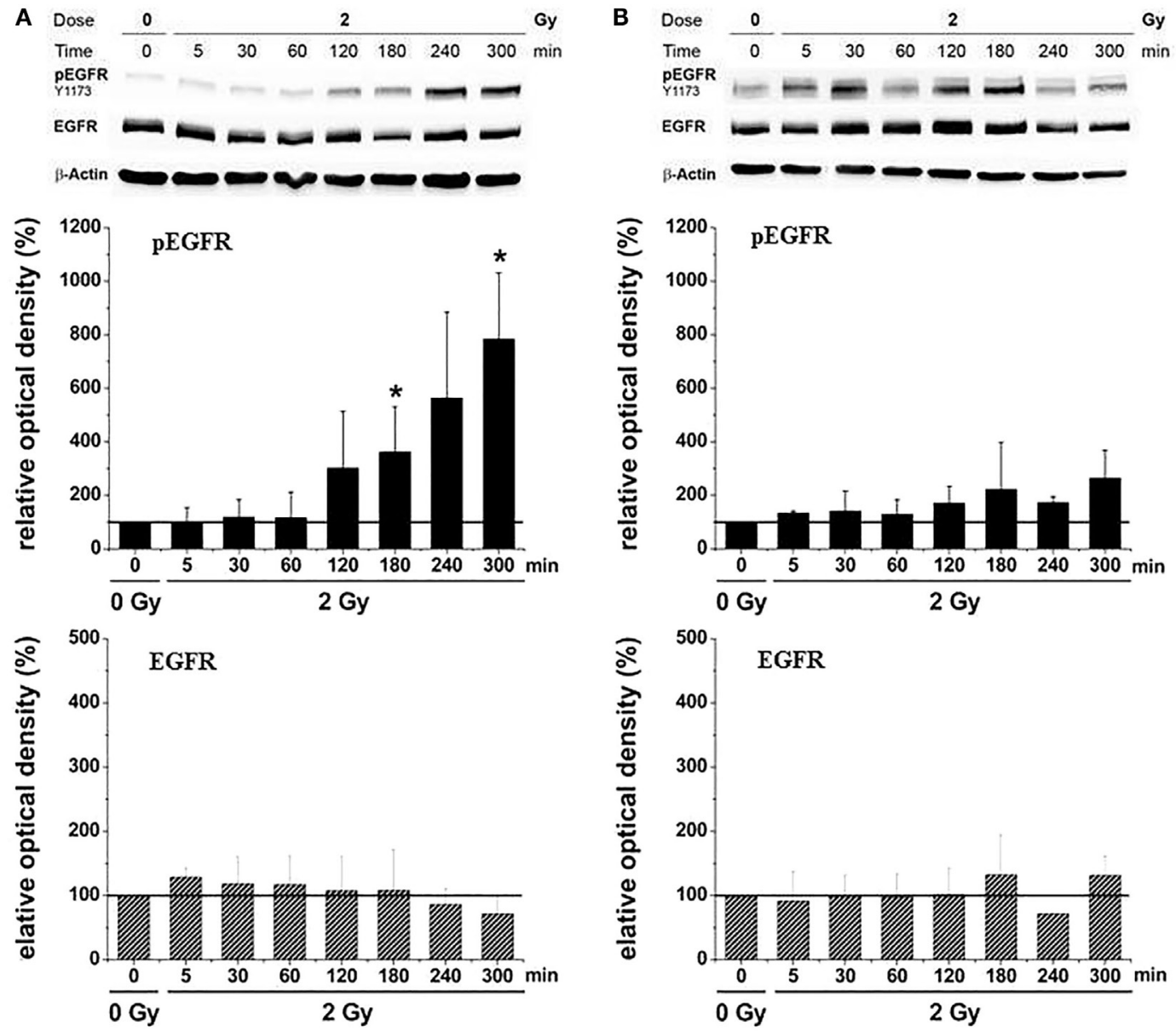

FIGURE 7 | Relative EGFR-phosphorylation (pEGFR) and total EGFR-protein (EGFR) in U87 glioma cells as a function of time after irradiation with 2 Gy [modified according to Ref. (19)] applying (A) X-rays and (B) carbon ions.

Four major conclusions were derived from the in vitro migration studies on glioma cells: (i) the impact of radiation on glioma cell migration depends on the migration assay used with both
$\mathrm{X}$-rays and carbon ions; (ii) under certain conditions and in a few glioma cell lines, clinically relevant doses of photons but not particles consistently increases cell migration; (iii) under a wide 
A

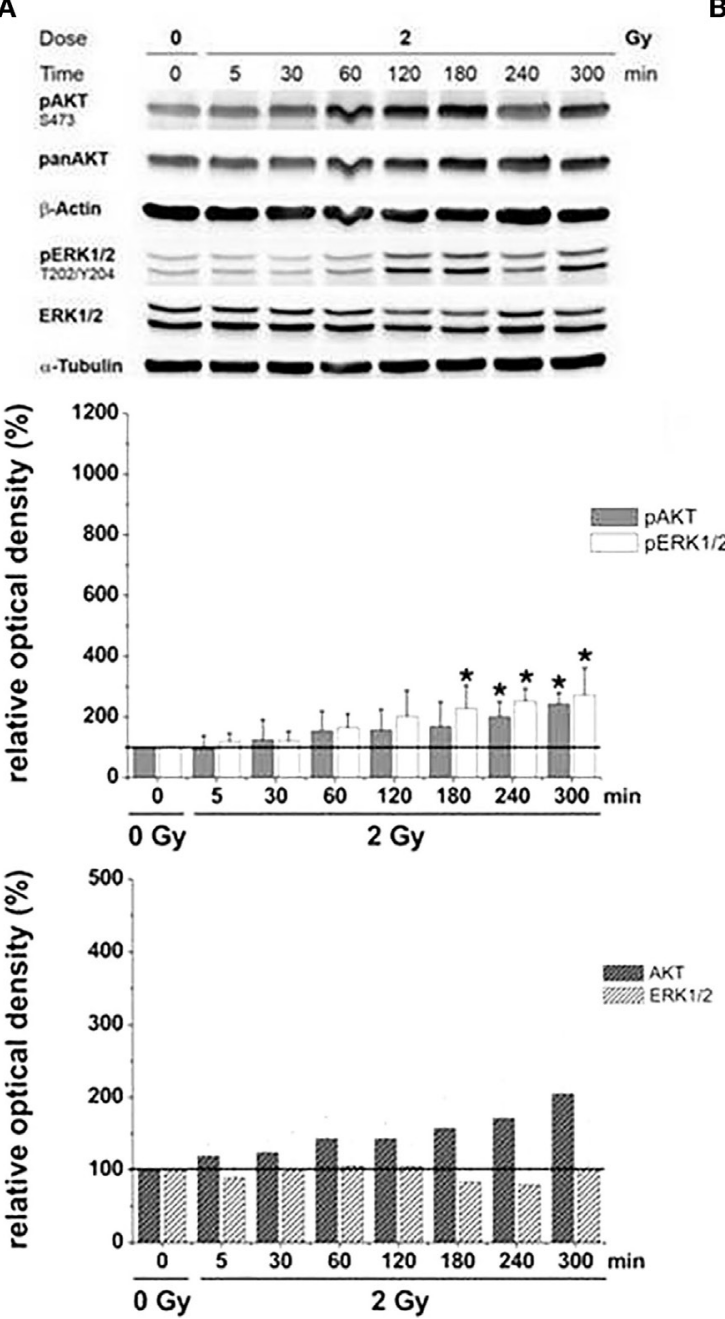

B
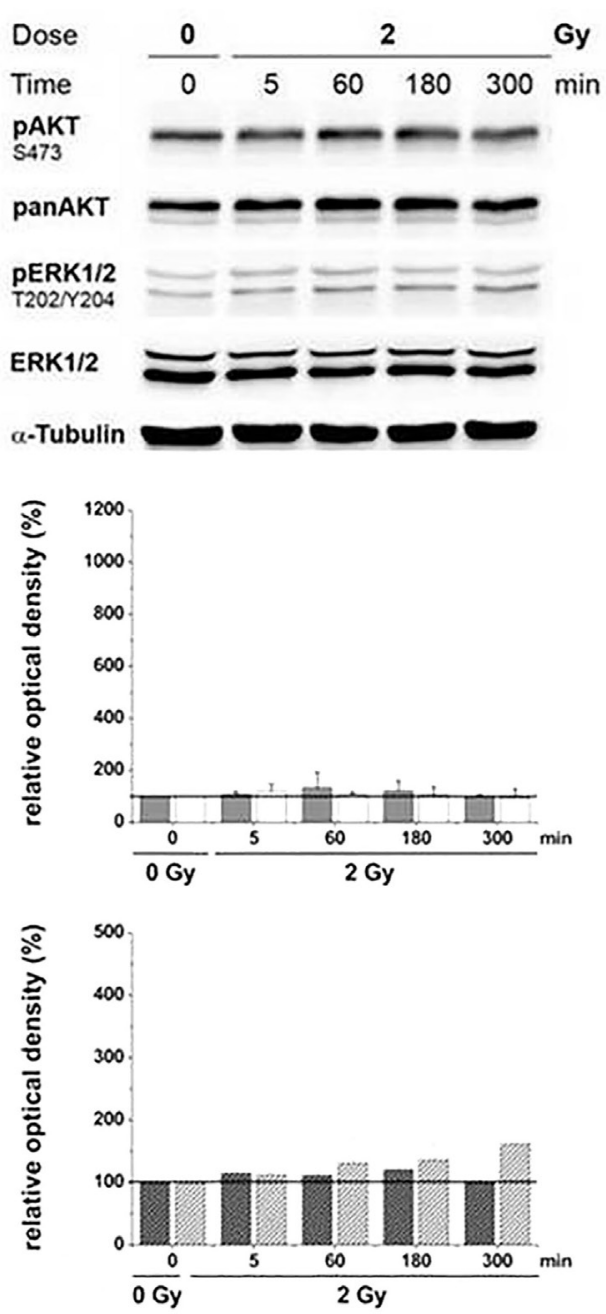

FIGURE 8 | Relative AKT/ERK-phosphorylation (pAKT/pERK) and total AKT/ERK-protein (AKT/ERK) in U87 glioma cells as a function of time after irradiation with 2 Gy [modified according to Ref. (19)] applying (A) X-rays and (B) carbon ions.

spectrum of conditions, glioma cell migration in vitro was either unaffected or reduced by ${ }^{12} \mathrm{C}^{6+}$ irradiation; and (iv) this differential between photon and particle irradiation may contribute to a higher efficiency of a local carbon ion treatment compared to $\mathrm{X}$-rays with regard to tumor recurrence.

\section{Studies on Early Events in Radiation- Induced Mucositis Using Organotypic Cultures of the Oral Mucosa Including Immune Cells}

Oral mucositis is a frequent complication of standardized radiotherapy in the clinic. There is an abundance of literature regarding preclinical and clinical research in this field, as reviewed recently, among others, by Mallick and colleagues (22). Much less is known, in this regard, about the side effects of particle irradiation, although the induction of mucositis by carbon ions has been clearly documented in patients already in 2002 (23). Although the number of centers for treatment with heavy charged particle is still undesirably low, the successful application of this technology in radiation oncology for the past two decades confers clinical relevance to particle treatment-associated mucositis (24).

A relatively novel aspect of radiation-associated mucositis results from the ambitious plans of several space agencies, in particular of the NASA and the ESA, for manned missions to the Mars. During such a mission which would last around 3 years, astronauts would be chronically exposed to cosmic radiation due to the absence of a protecting magnetic field. Space radiation consists of protons (87\%), $\alpha$-particles (12\%), and heavy ions (1\%) in solar particle events and galactic cosmic rays (25). In particular, highly ionizing heavy ions can be hardly shielded exposing the crew members to a serious medical safety risk (26), since the probability of getting a hit by heavy charged particles increases with time in space. It is obvious that the occurrence of oral or intestinal mucositis during a prolonged space flight would lead to hazardous situations. 
Oral mucositis as a result of X-ray exposure has been studied in numerous animal models, the advantages and limitations of which have been reviewed recently by Viet and co-workers (27). One major cutback of animal models that has been reported earlier is their unsuitability for the assessment of early molecular and pathophysiological events following irradiation (28).

Based on this background knowledge, we initiated a project, which was supported mainly by the GSI Darmstadt and the ESA, with investigations on early inflammatory events induced by heavy charged particle irradiation in organotypic cultures of the human oral mucosa. We re-activated a 3D culture model, previously established in our laboratory (29). The artificial mucosa, which was cultured at the liquid-gas interface, consisted of immortalized human gingival keratinocytes (IHGK) and immortalized human dermal fibroblasts (HH4ded), grown with or without PBMCs. The organotypic mucosa culture exhibited many features of the human oral mucosa, such as the formation of a basal membrane, a papillary shape of the epithelium-connective tissue boundary, or the differentiation status of the keratinocytes with regard to expression of keratins. A special technology was designed making it possible to irradiate the $3 \mathrm{D}$ cultures in the extended Bragg peak of the heavy ion beam including an appropriate dosimetry. Further details are described in Ref. (30).

Comparing the gene toxicity of X-rays with that of particles using the $\gamma \mathrm{H} 2 \mathrm{AX}$ technique, the superior effectiveness of heavy ions was confirmed by a roughly twofold higher number of foci per nucleus 4 and $48 \mathrm{~h}$ after treatment. This is shown in Figure 9 for $\mathrm{X}$-rays (Figure 9A) and ${ }^{12} \mathrm{C}^{6+}$ irradiation (Figure 9B).

Proinflammatory signs were quantitatively similar for both treatment modalities. For example, confocal microscopy made it possible to quantify the activation of NFKB by the assessment of the nuclear location of $\mathrm{NF \kappa B}$ p50. The corresponding results are depicted in Figures 10A,B for photons and particles, respectively. The release rates of the proinflammatory cytokines IL6 and IL8 from the organotypic cultures into the culture medium was registered using commercial ELISA assays [further details in Ref. (30)]. Figure 11 demonstrates a consistent and significant elevation of the release of both cytokines upon irradiation for both photons (Figures 11A,B) and particles (Figures 11C,D), albeit in the absence of a consistent dose dependency. Figures 12A,B illustrate for X-rays and carbon ions, respectively, that the addition of PBMC increases the radiation-induced release of IL6 and IL 8 by factors of $2-3$.

\section{DISCUSSION AND RESUME}

\section{Data from the Literature}

The very recent literature on heavy charged particle research clearly emphasizes the advantages of particle versus X-ray irradiation in a meanwhile broad spectrum of tumor entities as shown in a large number of patients mainly in Japan (more than 8,000 patients) and Germany $(31,32)$. Whereas different ions, such as carbon, helium, or protons (33), may be used in different treatment scenarios, carbon and helium appear to be superior to protons in the majority of cases (34). One review lately points out the importance of combining radiobiological and clinical research with carbon ion therapy (35-37). There is a common optimism among these authors with regard to further spread of charged particle treatment facilities world-wide $(31,32,34,38)$. Besides these clinical aspects, the already-mentioned significance of charged particle radiobiology for long-term exposition to space radiation during extended space flights has been detailed explicitly by an international consortium of experts in a recent article (39).

Several actual reports on cell and animal studies using carbon ions present $\mathrm{RBE}$ values, which are in a fairly good agreement with our data from multicell spheroid studies $(35,40,41)$. At the same time, data are presented that show a multitude of parameters to impact on RBE values, such as radiation dose, linear energy transfer (LET), and the model used for the derivation of RBE
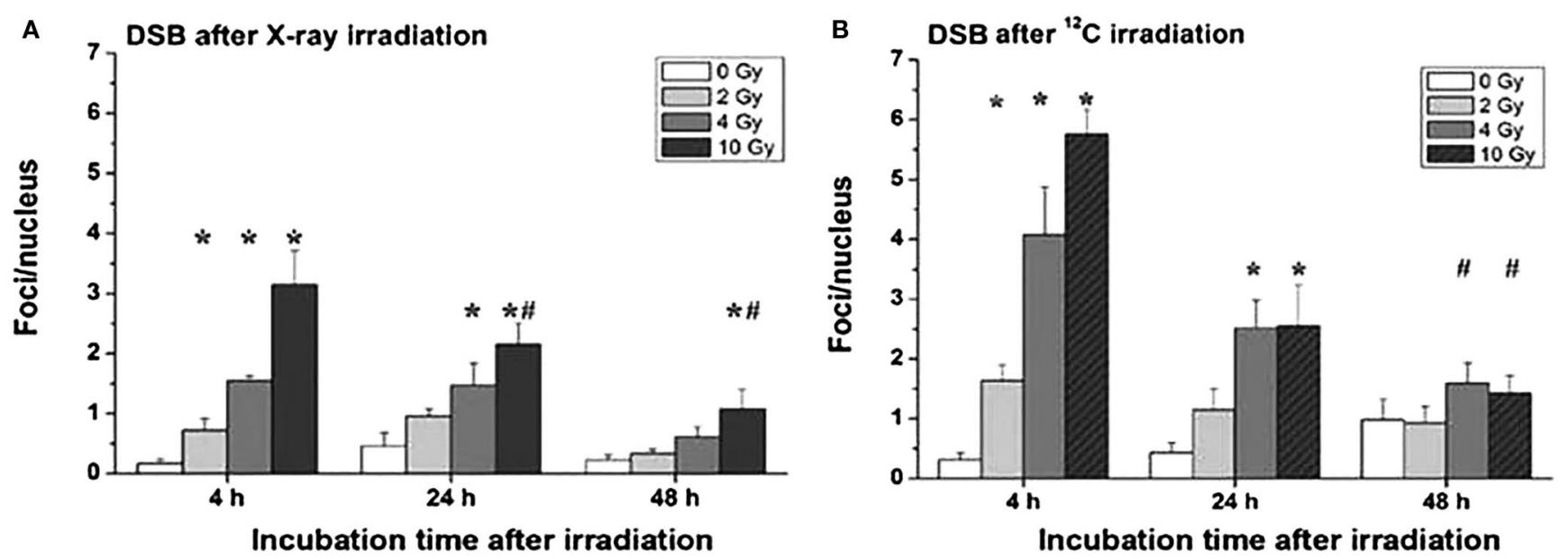

FIGURE 9 | Double-strand breaks (DSB) in organotypic cultures of oral mucosa, determined by evaluation of $\gamma \mathrm{H} 2 \mathrm{AX}$ stainings in immune fluorescence microscopy, as a function of radiation dose and time after radiation [modified according to Ref. (19)] applying (A) $X$-rays and (B) carbon ions. 
A

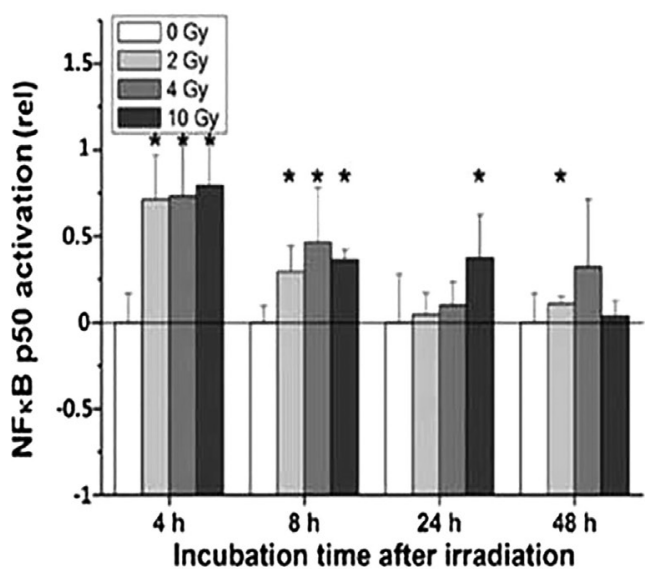

B NFxB p50 activation after ${ }^{12} \mathrm{C}$ irradiation

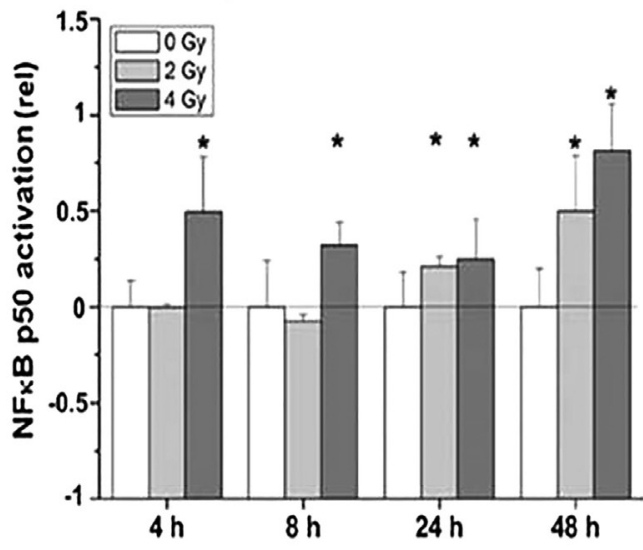

Incubation time after irradiation

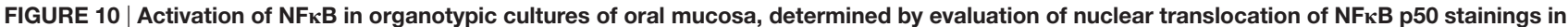
immune fluorescence confocal microscopy, as a function of radiation dose and time after radiation [modified according to Ref. (19)] applying (A) X-rays and (B) carbon ions.

A

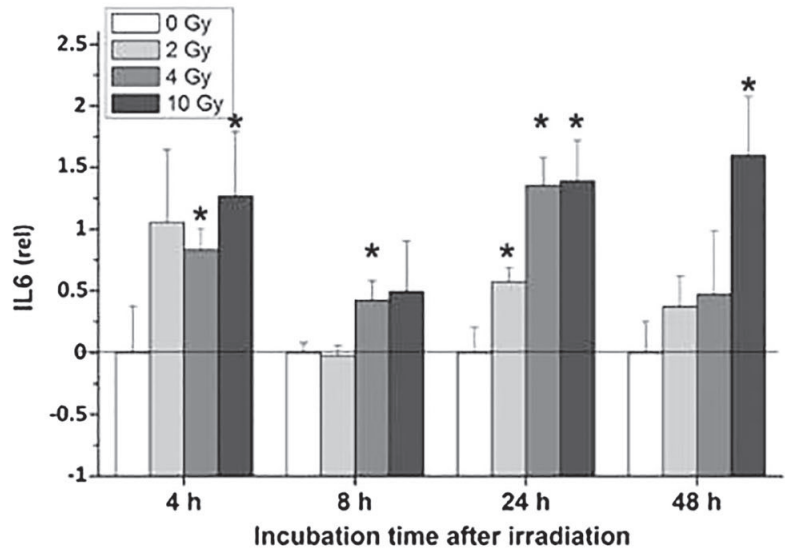

C

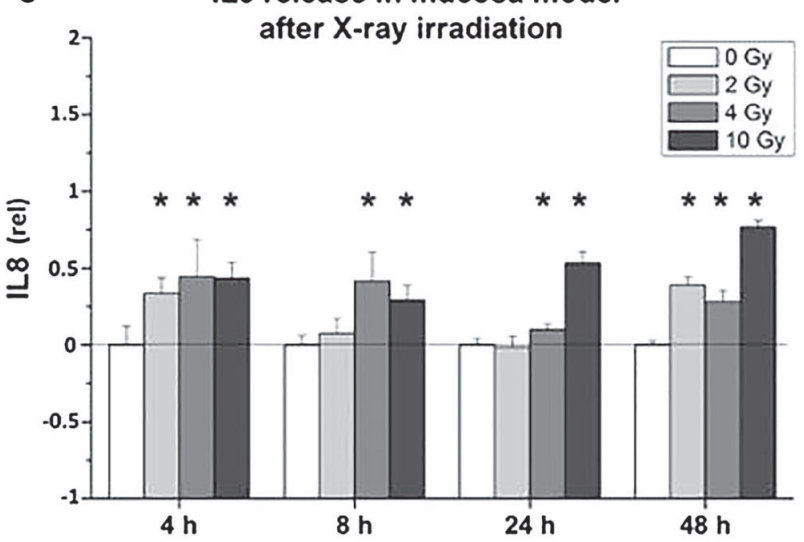

Incubation time after irradiation
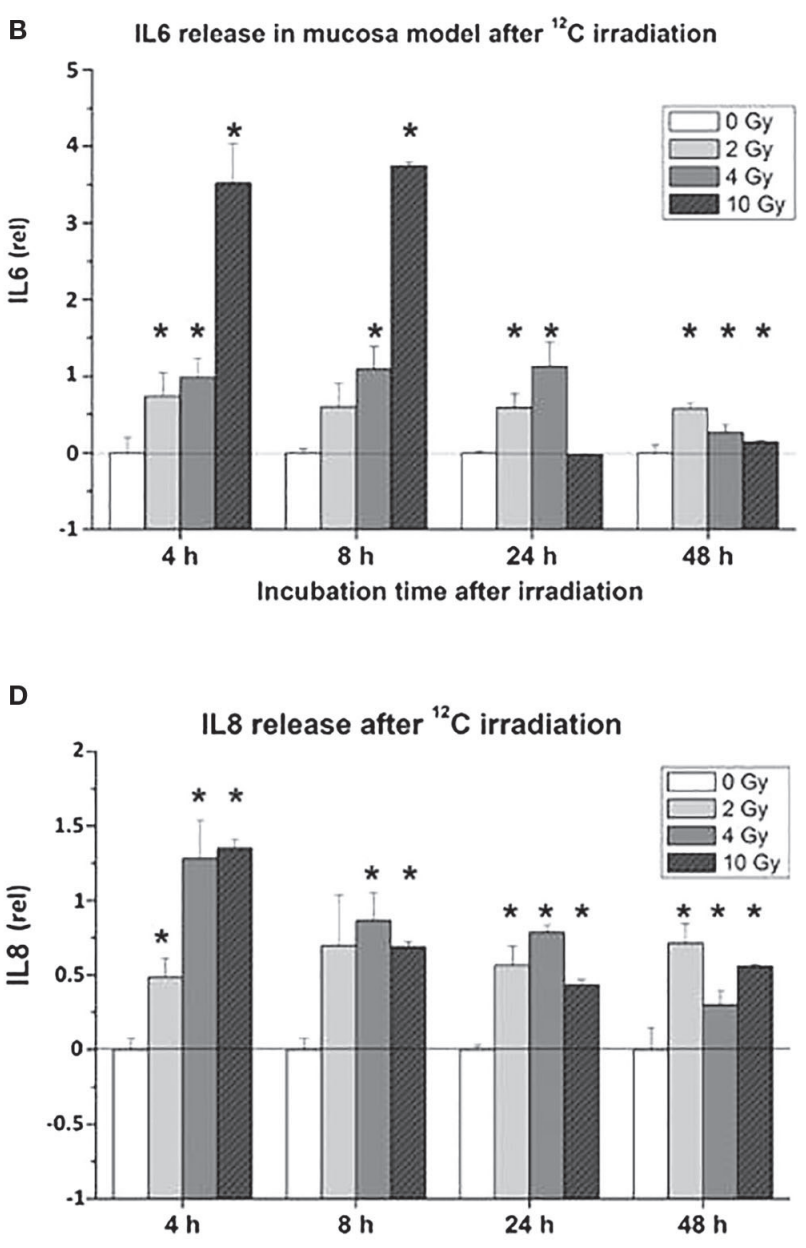

Incubation time after irradiation

FIGURE 11 | Cytokine release [IL6: (A,B); IL8: (C,D)] in organotypic cultures of oral mucosa, determined by commercial ELISA test, as a function of radiation dose and time after radiation [modified according to Ref. (19)] applying (A,C) X-rays and (B,D) carbon ions. 

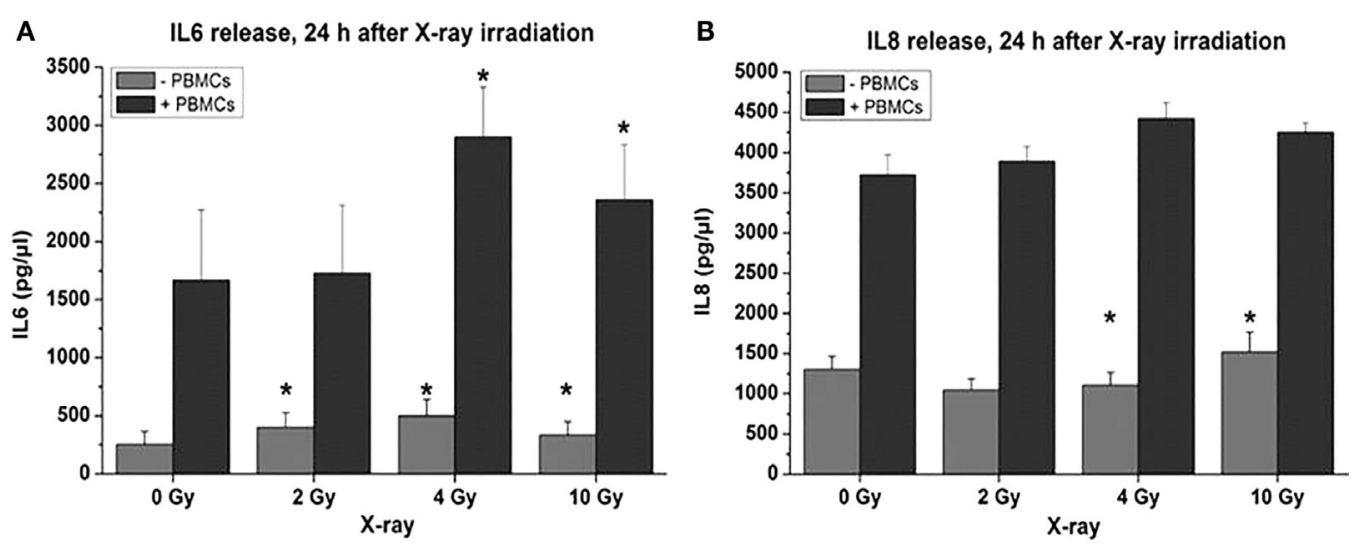

FIGURE 12 | Cytokine release following X-ray treatment of organotypic cultures of oral mucosa, determined by commercial ELISA test, as a function of radiation dose and time after radiation with or without coculturing of peripheral blood mononuclear cells [PBMCs; modified according to Ref. (19)]. (A) IL6 and (B) IL8.

$(35,37)$. Taking this into account, the derivation of RBE values for clinical dosimetry is still a matter of debate (37). In a recent simulation study on hypoxia in clinical tumors treated with carbon ions, OER were found that corresponded well to our data from MCS (42). The authors also point to the existence of a nonnegligible oxygen effect that can influence the outcome of carbon ion therapy at low LET in the spread-out Bragg peak. A recent investigation using a carbon ion beam or X-rays for irradiating neuro-spheres of human GBM cells documents the occurrence of a multicellular resistance that was much less pronounced - but still detectable - with particle radiation compared to photons (43). As many studies with $\mathrm{X}$-rays before, this investigation demonstrates a multicellular radioresistance, eventually termed contact effect, to exist for carbon ions as well. This is in contrast to the multicellular radiosensitization, which we have shown for charged particle irradiation of planar tumor cell multilayers compared to corresponding single cells [(8); see above].

There are two recent reports confirming our observation on charged particle effects on cell migration and related signaling pathways. Simon et al. (44) were able to show that migration of meningioma cells was promoted by photon but not by carbon ion irradiation. Our results on an increased cell migration associated with an elevated phosphorylation status of the EGFR and AKT-ERK1/2 pathway following X-ray but not carbon irradiation was partially confirmed by corresponding findings of Jin and colleagues (45). These data are in accordance with previous observations regarding the inhibitory influence of heavy charged particle irradiation on tumor cell migration and formation of metastasis $(21,46)$. Recent reviews, such as the article by Fujita (47), mirror a still ongoing and partially controversial debate with regard to the impact of radiation on cancer cell motility, invasiveness, and metastatic potential. Interestingly, a recent experimental study using carbon ion irradiation in a rat prostate carcinoma has demonstrated an increase in the metastatic rate upon treatment (48).

As a brief resume, the experimental therapeutics part of the data compiled clearly demonstrates the efficiency of ${ }^{12} \mathrm{C}^{6+}$ irradiation to be consistently higher than that of conventional $\mathrm{X}$-rays; this is mirrored by RBE values for particles versus photons of $>1.0$ and up to 4.3 under hypoxic conditions. Since hypoxia occurs in $50-60 \%$ of all human solid tumors (49), it is of high clinical relevance that ${ }^{12} \mathrm{C}^{6+}$ irradiation is much more efficient than conventional radiation under these conditions. Whereas OER values are close to 3 for X-rays, an OER value of 1.4 was derived for carbon ions. Here, multicellular tumor spheroids proved themselves as useful models for quantitative studies on the radiobiology of heavy charged particles. In the experimental inflammation part of the data compilation, organotypic cultures of the oral mucosa were shown to be useful for investigations on immediate and early inflammatory events, i.e., within a few hours up to 2 days following ${ }^{12} \mathrm{C}^{6+}$ radiation treatment. Besides the quantification of gene toxicity and proinflammatory cytokine release, the consistent, immediate, and early, as well as dose-dependent activation of $\mathrm{NF \kappa B}$ by ${ }^{12} \mathrm{C}^{6+}$ irradiation of oral mucosa cultures is one of the core results of this part of the studies.

\section{AUTHOR CONTRIBUTIONS}

Both the authors listed have made substantial, direct, and intellectual contribution to the work and approved it for publication.

\section{ACKNOWLEDGMENTS}

Special thanks are given to Nicole Averbeck, Gerhard Kraft, Michael Scholz, and Gisela Taucher-Scholz at the GSI Darmstadt and to Nils Cordes at Oncoray, University of Dresden, for many helpful discussions and for their professional support of the projects.

\section{FUNDING}

This work was supported by the Gesellschaft für Schwerionenforschung (GSI) Darmstadt, Germany, the European Space Agency (ESA)/German Aerospace Center (DLR)/Federal Ministry of Economics and Technology (BMWi): 50 WB 0926 and by the Deutsche Forschungsgemeinschaft (DFG; MU 576/17-1). 


\section{REFERENCES}

1. Schulz-Ertner D, Nikoghosyan A, Didinger B, Debus J. Carbon ion radiation therapy for chordomas and low grade chondrosarcomas - current status of the clinical trials at GSI. Radiother Oncol (2004) 73(Suppl 2):S53-6. doi:10.1016/ S0167-8140(04)80014-8

2. Sutherland RM, McCredie JA, Inch WR. Growth of multicell spheroids in tissue culture as a model of nodular carcinomas. J Natl Cancer Inst (1971) 46(1):113-20.

3. Sutherland RM. Cell and environment interactions in tumor microregions: the multicell spheroid model. Science (1988) 240(4849):177-84. doi:10.1126/ science. 2451290

4. Mueller-Klieser WF, Sutherland RM. Influence of convection in the growth medium on oxygen tensions in multicellular tumor spheroids. Cancer Res (1982) 42(1):237-42.

5. Sutherland RM, Sordat B, Bamat J, Gabbert H, Bourrat B, Mueller-Klieser W. Oxygenation and differentiation in multicellular spheroids of human colon carcinoma. Cancer Res (1986) 46(10):5320-9.

6. Hirschhaeuser F, Menne H, Dittfeld C, West J, Mueller-Klieser W, KunzSchughart LA. Multicellular tumor spheroids: an underestimated tool is catching up again. J Biotechnol (2010) 148(1):3-15. doi:10.1016/j. jbiotec.2010.01.012

7. Staab A, Zukowski D, Walenta S, Scholz M, Mueller-Klieser W. Response of Chinese hamster v79 multicellular spheroids exposed to high-energy carbon ions. Radiat Res (2004) 161(2):219-27. doi:10.1667/RR3113

8. Topsch J, Scholz M, Mueller-Klieser W. Radiobiological characterization of human tumor cell multilayers after conventional and particle irradiation. Radiat Res (2007) 167(6):645-54. doi:10.1667/RR0775.1

9. Goetze K, Scholz M, Taucher-Scholz G, Mueller-Klieser W. The impact of conventional and heavy ion irradiation on tumor cell migration in vitro. Int J Radiat Biol (2007) 83(11-12):889-96. doi:10.1080/09553000701753826

10. Rieken S, Habermehl D, Mohr A, Wuerth L, Lindel K, Weber K, et al. Targeting alphanubeta3 and alphanubeta5 inhibits photon-induced hypermigration of malignant glioma cells. Radiat Oncol (2011) 6:132. doi:10.1186/1748-717X-6-132

11. Wild-Bode C, Weller M, Rimner A, Dichgans J, Wick W. Sublethal irradiation promotes migration and invasiveness of glioma cells: implications for radiotherapy of human glioblastoma. Cancer Res (2001) 61(6):2744-50.

12. Cordes N, Hansmeier B, Beinke C, Meineke V, van Beuningen D. Irradiation differentially affects substratum-dependent survival, adhesion, and invasion of glioblastoma cell lines. Br J Cancer (2003) 89(11):2122-32. doi:10.1038/ sj.bjc.6601429

13. Eke I, Storch K, Kastner I, Vehlow A, Faethe C, Mueller-Klieser W, et al. Threedimensional invasion of human glioblastoma cells remains unchanged by X-ray and carbon ion irradiation in vitro. Int J Radiat Oncol Biol Phys (2012) 84(4):e515-23. doi:10.1016/j.ijrobp.2012.06.012

14. Rieken S, Habermehl D, Wuerth L, Brons S, Mohr A, Lindel K, et al. Carbon ion irradiation inhibits glioma cell migration through downregulation of integrin expression. Int J Radiat Oncol Biol Phys (2012) 83(1):394-9. doi:10.1016/j. ijrobp.2011.06.2004

15. Schlegel J, Stumm G, Brandle K, Merdes A, Mechtersheimer G, Hynes NE, et al. Amplification and differential expression of members of the erbB-gene family in human glioblastoma. J Neurooncol (1994) 22(3):201-7. doi:10.1007/ BF01052920

16. Nieder C, Pawinski A, Dalhaug A, Andratschke N. A review of clinical trials of cetuximab combined with radiotherapy for non-small cell lung cancer. Radiat Oncol (2012) 7(1):3. doi:10.1186/1748-717X-7-3

17. Eppenberger U, Mueller $H$. Growth factor receptors and their ligands. J Neurooncol (1994) 22(3):249-54. doi:10.1007/BF01052929

18. Dittmar T, Husemann A, Schewe Y, Nofer JR, Niggemann B, Zanker KS, et al. Induction of cancer cell migration by epidermal growth factor is initiated by specific phosphorylation of tyrosine 1248 of c-erbB-2 receptor via EGFR. FASEB J (2002) 16(13):1823-5. doi:10.1096/fj.02-0096fje

19. Stahler C, Roth J, Cordes N, Taucher-Scholz G, Mueller-Klieser W. Impact of carbon ion irradiation on epidermal growth factor receptor signaling and glioma cell migration in comparison to conventional photon irradiation. Int J Radiat Biol (2013) 89(6):454-61. doi:10.3109/09553002.2013.766769
20. Mukherjee B, McEllin B, Camacho CV, Tomimatsu N, Sirasanagandala S, Nannepaga S, et al. EGFRvIII and DNA double-strand break repair: a molecular mechanism for radioresistance in glioblastoma. Cancer Res (2009) 69(10):4252-9. doi:10.1158/0008-5472.CAN-08-4853

21. Ogata $\mathrm{T}$, Teshima $\mathrm{T}$, Inaoka $\mathrm{M}$, Minami $\mathrm{K}$, Tsuchiya $\mathrm{T}$, Isono $\mathrm{M}$, et al. Carbon ion irradiation suppresses metastatic potential of human non-small cell lung cancer A549 cells through the phosphatidylinositol-3-kinase/Akt signaling pathway. J Radiat Res (2011) 52(3):374-9. doi:10.1269/jrr.10102

22. Mallick S, Benson R, Rath GK. Radiation induced oral mucositis: a review of current literature on prevention and management. Eur Arch Otorhinolaryngol (2015). doi:10.1007/s00405-015-3694-6

23. Schulz-Ertner D, Haberer T, Scholz M, Thilmann C, Wenz F, Jakel O, et al. Acute radiation-induced toxicity of heavy ion radiotherapy delivered with intensity modulated pencil beam scanning in patients with base of skull tumors. Radiother Oncol (2002) 64(2):189-95. doi:10.1016/ S0167-8140(02)00153-6

24. Loeffler JS, Durante M. Charged particle therapy - optimization, challenges and future directions. Nat Rev Clin Oncol (2013) 10(7):411-24. doi:10.1038/ nrclinonc.2013.79

25. Maalouf M, Durante M, Foray N. Biological effects of space radiation on human cells: history, advances and outcomes. J Radiat Res (2011) 52(2):12646. doi:10.1269/jrr.10128

26. Durante M, Cucinotta FA. Heavy ion carcinogenesis and human space exploration. Nat Rev Cancer (2008) 8(6):465-72. doi:10.1038/nrc2391

27. Viet CT, Corby PM, Akinwande A, Schmidt BL. Review of preclinical studies on treatment of mucositis and associated pain. J Dent Res (2014) 93(9):868-75. doi:10.1177/0022034514540174

28. Yeoh A, Gibson R, Yeoh E, Bowen J, Stringer A, Giam K, et al. Radiation therapy-induced mucositis: relationships between fractionated radiation, NF-kappaB, COX-1, and COX-2. Cancer Treat Rev (2006) 32(8):645-51. doi:10.1016/j.ctrv.2006.08.005

29. Kunz-Schughart LA, Mueller-Klieser W. Three-dimensional culture. 3rd ed. In: Masters JRW, editor. Animal Cell Culture: A Practical Approach. Oxford; New York; Tokyo: IRL Press at Oxford University Press (2000). p. 123-48.

30. Tschachojan V, Schroer H, Averbeck N, Mueller-Klieser W. Carbon ions and $\mathrm{X}$ rays induce proinflammatory effects in $3 \mathrm{D}$ oral mucosa models with and without PBMCs. Oncol Rep (2014) 32(5):1820-8. doi:10.3892/or.2014.3441

31. Kamada T, Tsujii H, Blakely EA, Debus J, De NW, Durante M, et al. Carbon ion radiotherapy in Japan: an assessment of 20 years of clinical experience. Lancet Oncol (2015) 16(2):e93-100. doi:10.1016/S1470-2045(14)70412-7

32. Marx V. Cancer treatment: sharp shooters. Nature (2014) 508(7494):133-8. doi:10.1038/508133a

33. Tommasino F, Durante M. Proton radiobiology. Cancers (Basel) (2015) 7(1):353-81. doi:10.3390/cancers7010353

34. Grun R, Friedrich T, Kramer M, Zink K, Durante M, EngenhartCabillic R, et al. Assessment of potential advantages of relevant ions for particle therapy: a model based study. Med Phys (2015) 42(2):1037-47. doi:10.1118/1.4905374

35. Saager M, Glowa C, Peschke P, Brons S, Grun R, Scholz M, et al. Split dose carbon ion irradiation of the rat spinal cord: dependence of the relative biological effectiveness on dose and linear energy transfer. Radiother Oncol (2015) 117(2):358-63. doi:10.1016/j.radonc.2015.07.006

36. Schlaff CD, Krauze A, Belard A, O'Connell JJ, Camphausen KA. Bringing the heavy: carbon ion therapy in the radiobiological and clinical context. Radiat Oncol (2014) 9(1):88. doi:10.1186/1748-717X-9-88

37. Steinstrater O, Scholz U, Friedrich T, Kramer M, Grun R, Durante M, et al Integration of a model-independent interface for RBE predictions in a treatment planning system for active particle beam scanning. Phys Med Biol (2015) 60(17):6811-31. doi:10.1088/0031-9155/60/17/6811

38. Tomlinson DC, Baldo O, Harnden P, Knowles MA. FGFR3 protein expression and its relationship to mutation status and prognostic variables in bladder cancer. J Pathol (2007) 213(1):91-8. doi:10.1002/path.2207

39. Barcellos-Hoff MH, Blakely EA, Burma S, Fornace AJ Jr, Gerson S, Hlatky L, et al. Concepts and challenges in cancer risk prediction for the space radiation environment. Life Sci Space Res (Amst) (2015) 6:92-103. doi:10.1016/j. lssr.2015.07.006 
40. Ferrandon S, Magne N, Battiston-Montagne P, Hau-Desbat NH, Diaz O, Beuve $\mathrm{M}$, et al. Cellular and molecular portrait of eleven human glioblastoma cell lines under photon and carbon ion irradiation. Cancer Lett (2015) 360(1):10-6. doi:10.1016/j.canlet.2015.01.025

41. Sorensen BS, Horsman MR, Alsner J, Overgaard J, Durante M, Scholz M, et al. Relative biological effectiveness of carbon ions for tumor control, acute skin damage and late radiation-induced fibrosis in a mouse model. Acta Oncol (2015) 54(9):1623-30. doi:10.3109/0284186X.2015.1069890

42. Antonovic L, Lindblom E, Dasu A, Bassler N, Furusawa Y, Toma-Dasu I. Clinical oxygen enhancement ratio of tumors in carbon ion radiotherapy: the influence of local oxygenation changes. J Radiat Res (2014) 55(5):902-11. doi:10.1093/jrr/rru020

43. Takahashi M, Hirakawa H, Yajima H, Izumi-Nakajima N, Okayasu R, Fujimori A. Carbon ion beam is more effective to induce cell death in sphere-type A172 human glioblastoma cells compared with X-rays. Int J Radiat Biol (2014) 90(12):1125-32. doi:10.3109/09553002.2014.927933

44. Simon F, Dittmar JO, Brons S, Orschiedt L, Urbschat S, Weber KJ, et al. Integrin-based meningioma cell migration is promoted by photon but not by carbon-ion irradiation. Strahlenther Onkol (2015) 191(4):347-55. doi:10.1007/ s00066-014-0778-y

45. Jin X, Li F, Zheng X, Liu Y, Hirayama R, Liu X, et al. Carbon ions induce autophagy effectively through stimulating the unfolded protein response and subsequent inhibiting Akt phosphorylation in tumor cells. Sci Rep (2015) 5:13815. doi:10.1038/srep13815
46. Ogata T, Teshima T, Kagawa K, Hishikawa Y, Takahashi Y, Kawaguchi A, et al. Particle irradiation suppresses metastatic potential of cancer cells. Cancer Res (2005) 65(1):113-20.

47. Fujita M, Yamada S, Imai T. Irradiation induces diverse changes in invasive potential in cancer lines. Semin Cancer Biol (2015) 35:45-52. doi:10.1016/j. semcancer.2015.09.003

48. Karger CP, Scholz M, Huber PE, Debus J, Peschke P. Photon and carbon ion irradiation of a rat prostate carcinoma: does a higher fraction number increase the metastatic rate? Radiat Res (2014) 181(6):623-8. doi:10.1667/ RR13611.1

49. Harrison L, Blackwell K. Hypoxia and anemia: factors in decreased sensitivity to radiation therapy and chemotherapy? Oncologist (2004) 9(Suppl 5):31-40. doi:10.1634/theoncologist.9-90005-31

Conflict of Interest Statement: The authors declare that the research was conducted in the absence of any commercial or financial relationships that could be construed as a potential conflict of interest.

Copyright (c) 2016 Walenta and Mueller-Klieser. This is an open-access article distributed under the terms of the Creative Commons Attribution License (CC BY).

The use, distribution or reproduction in other forums is permitted, provided the original author(s) or licensor are credited and that the original publication in this journal is cited, in accordance with accepted academic practice. No use, distribution or reproduction is permitted which does not comply with these terms. 